\title{
Level 1 Electric Vehicle Charging Stations at the Workplace
}

Margaret Smith, Energetics Incorporated

July 2016

Prepared for the U.S. Department of Energy Vehicle Technologies Office
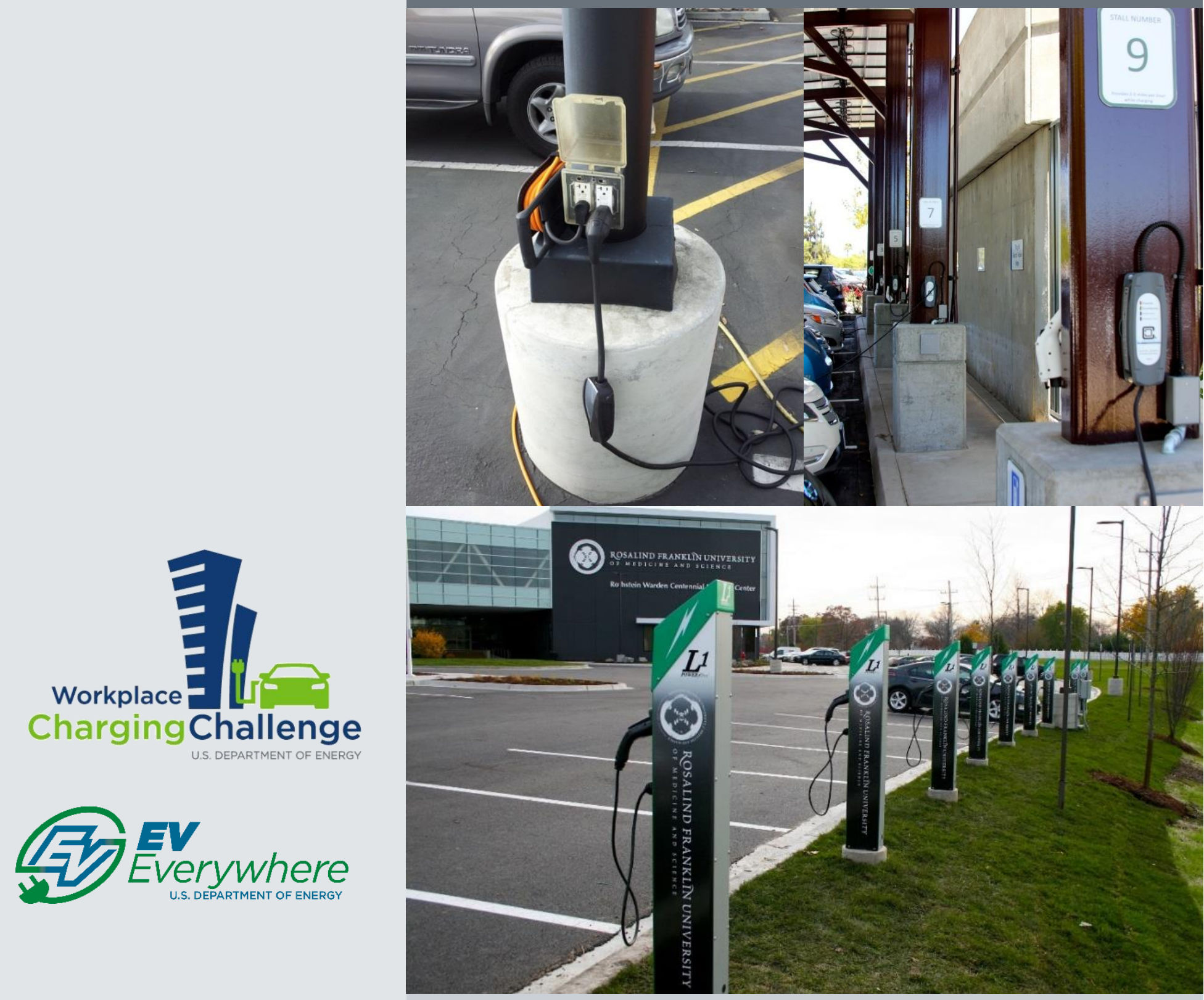


\section{Table of Contents}

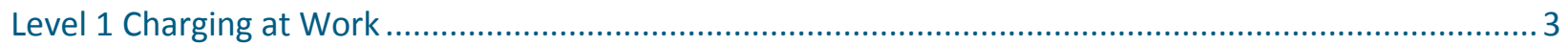

Scenario A: Making a Level 1 Electrical Outlet Available ....................................................................... 4

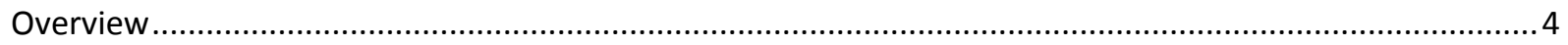

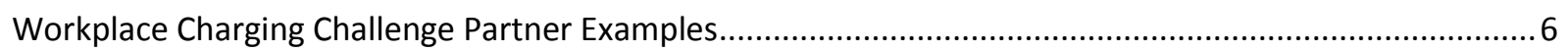

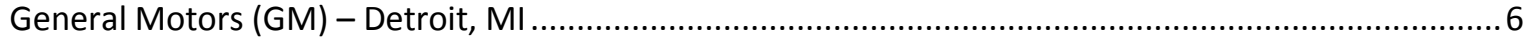

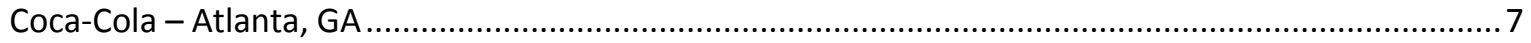

Estimated Costs for Scenario A (Making an Electrical Outlet Available) ….................................................... 7

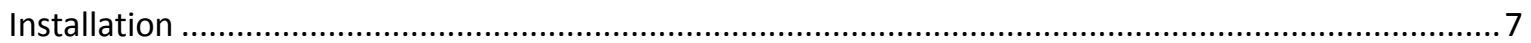

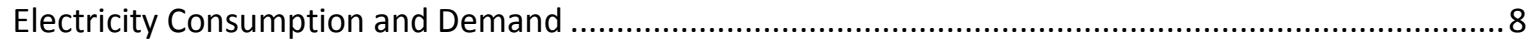

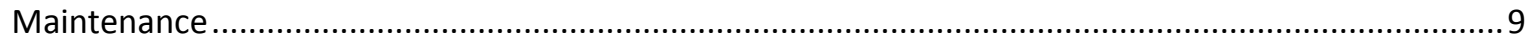

Sample Employee Fee for Scenario A (Making an Electrical Outlet Available) ........................................... 9

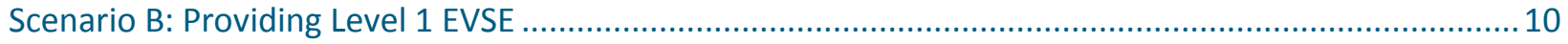

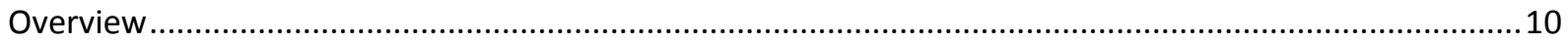

Workplace Charging Challenge Partner Examples................................................................................... 10

Melink - Milford, $\mathrm{OH}$

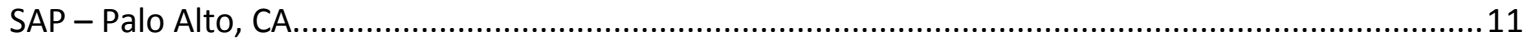

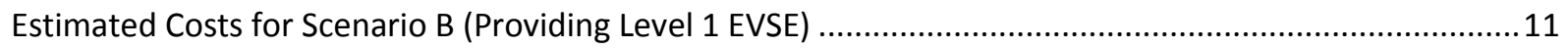

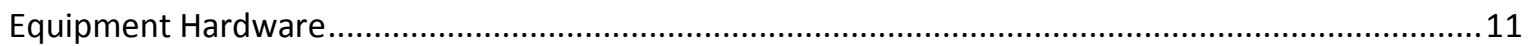

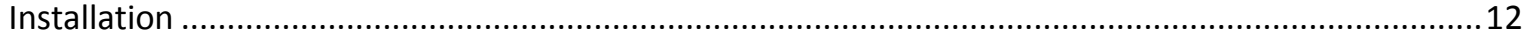

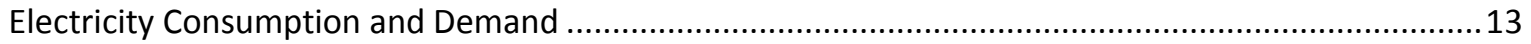

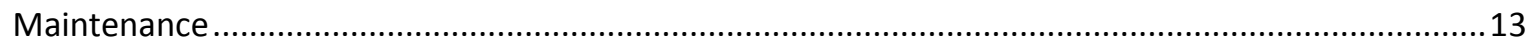

Sample Employee Fee for Scenario B (Providing Wall-Mounted Level 1 EVSE) ….....................................13

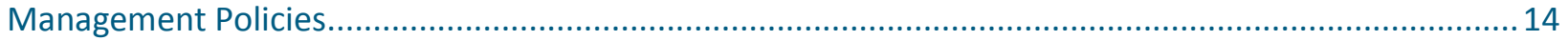

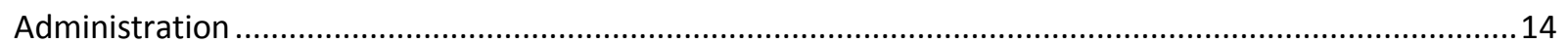

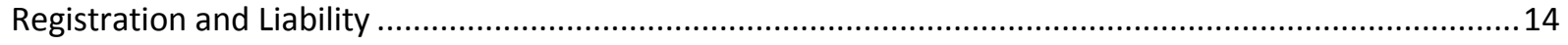

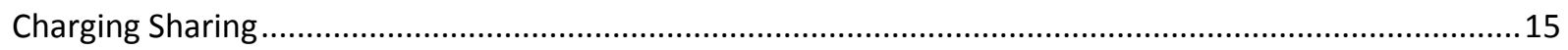

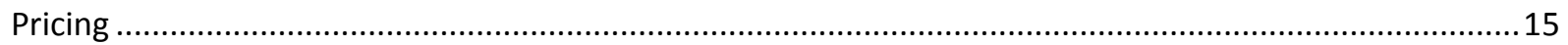

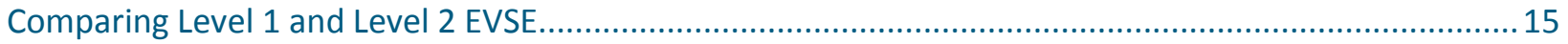

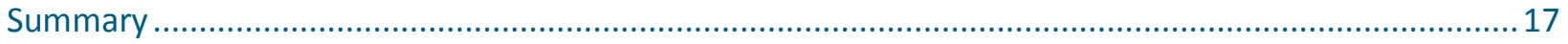




\section{Level 1 Charging at Work}

Level 1 charging (110-120 V) can be a good fit for many workplace charging programs. For electric vehicles typically purchased by most employees, Level 1 charging often has sufficient power to fully restore vehicle driving range during work hours. Level 1 electric vehicle supply equipment (EVSE) replenishes 2 to 5 miles of range during one hour of charging. ${ }^{1}$ If plug-in electric vehicle (PEV) drivers park their cars for 6.5-8 hours each day, they can replenish 30 to 40 miles in one work day. ${ }^{2}$ More than $90 \%$ of employees in the United States commute less than 35 miles, ${ }^{3}$ which means that Level 1 charging could adequately replenish the battery capacity used to travel to work. Having access to Level 1 charging at home and at work could meet the charging needs of over $92 \%$ of U.S. drivers' workday travel. ${ }^{4}$ While the installation and management of PEV charging stations requires planning, the U.S. Department of Energy (DOE) Workplace Charging Challenge, launched in 2013, aims to support these efforts. This document highlights the experiences of a selection of Workplace Charging Challenge partners that use Level 1 charging.

Workplaces can provide Level 1 charging using two

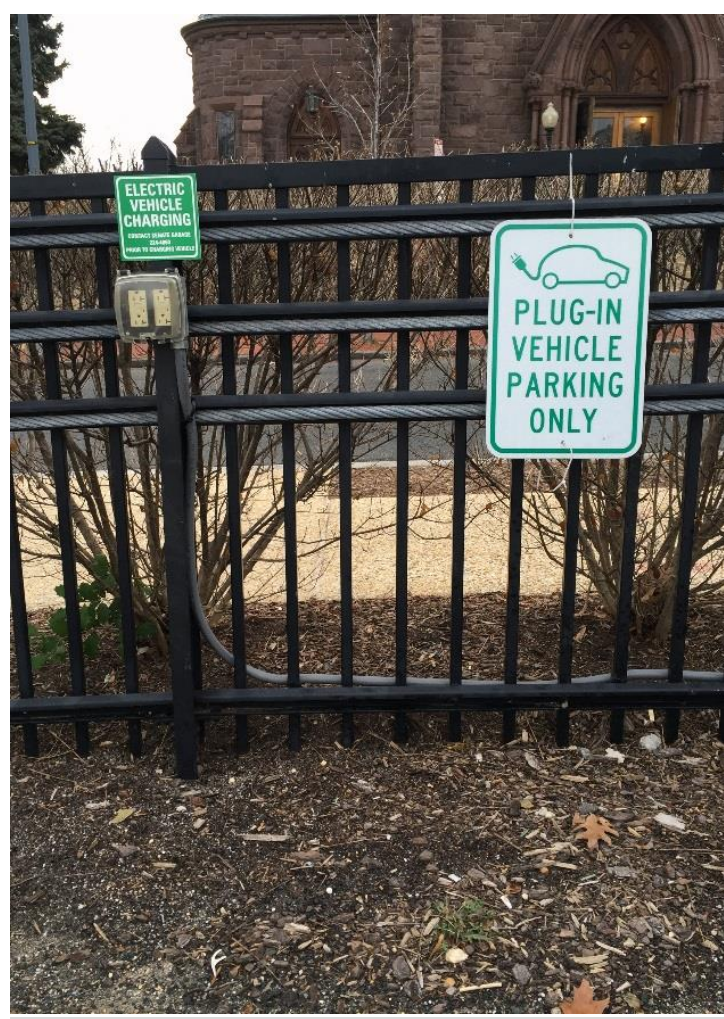

Photo 1.This Level 1 outlet is available for electric vehicle charging at the U.S. Senate parking lot. Photo from Sarah Olexsak, DOE. main ways: (1) using a Level 1 outlet for employees to plug in their own charging equipment, and (2) providing a Level 1 charging station with the EVSE charging equipment installed at the workplace. In either situation, having a proper workplace charging policy in place is critical to program success. For instance, appropriate signage, a policy for who can use the charging stations, and a well-thought-out fee structure can have a large impact on how happy the employer and employees are with the workplace charging program.

To obtain estimates for a specific project, contact electricians and EVSE manufacturers.
When evaluating the cost of any PEV charging station, consider the hardware, installation, electricity consumption charges, electricity demand charges, and maintenance. Offering an electrical outlet is usually the lowest-cost scenario. Providing EVSE has the additional cost of the purchased equipment. Generally, a pedestal-mounted EVSE has higher installation costs than a wall-mounted EVSE. If a

\footnotetext{
${ }^{1}$ Alternative Fuels Data Center - http://www.afdc.energy.gov/fuels/electricity_infrastructure.html.

${ }^{2}$ Assuming a Level 1 EVSE that replenishes 5 miles of range during one hour of charging.

${ }^{3}$ U.S. Department of Transportation (DOT) Bureau of Transportation Statistics' October 2003 OmniStats report, Volume 3, Issue 4.

${ }^{4}$ Charging Ahead on the Transition to Electric Vehicles with Standard 120 V Wall Outlets, S. Saxena. Lawrence Berkeley National Laboratory. Applied Energy. June 2015.
} 
site requires electrical service upgrades to accommodate the power used by PEV charging stations, installation costs can rise significantly. To obtain estimates for a specific project, contact electricians and EVSE manufacturers.

\section{Scenario A: Making a Level 1 Electrical Outlet Available}

\section{Overview}

Most PEVs come with a cordset that on one end has a standard, three-prong household plug that plugs into a Level 1 outlet (110-120 V) and on the other end has an SAE J1772 standard connector that plugs into the vehicle. Making Level 1 charging available to an employee could simply mean offering electrical outlets for drivers to plug in their own cordsets. Offering an outlet for charging is usually the lowest-cost option for providing workplace charging because it requires no EVSE purchase and the installation costs are minimal (see Estimated Costs for Scenario A section below).

Employers that offer an outlet for employee charging rather than purchase and install

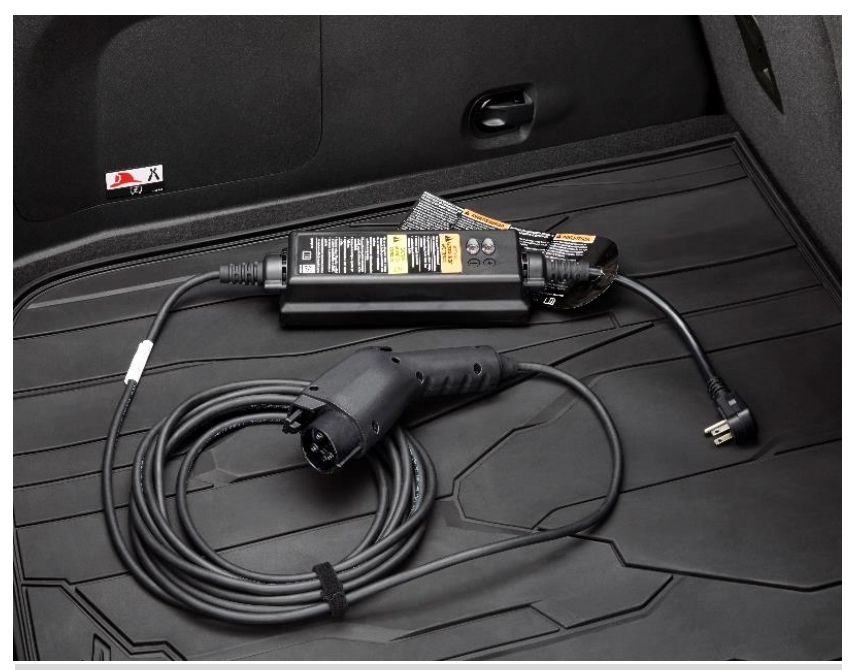

Photo 2. This Level 1 cordset comes standard with a MY16 and MY17 Chevrolet Volt. Photo from GM

charging equipment do not have access to the selection of management features available with networked Level 2 EVSE. They can still manage employee charging habits but will need to consider separate management solutions. Employers that want to track the energy consumed by PEV charging at the Level 1 outlet can install an energy monitor near the control panel for the PEV charging circuit. Energy monitors are available that can track the power consumed during each charging event and provide online access to the information. Organizations that want to ensure the outlet is used only by certain individuals can use an outlet cover and padlock to restrict access.

Although a Level 1 outlet may be the preferred workplace charging scenario for an employer, it may not be the preferred scenario for employees. Some employees may consider it a hassle to bring and use their own cordsets and would prefer to have Level 1 EVSE installed at the workplace. Many PEV drivers prefer to leave their cordsets at home for convenient charging at home, or they may have concerns about vandalism or cordset theft. Some cordsets have an anti-theft feature that allows the driver to use a simple padlock to prevent anyone from removing the connector from the vehicle without a key. If the charging station is outdoors and there is inclement weather, drivers may object to putting a wet, snow-covered, or muddy cordset back in their car trunks after charging. For plug-in hybrid electric vehicles (PHEVs), drivers can simply leave their cordsets in the vehicle and use gasoline if they are concerned about inclement weather. Despite the disadvantages, most employees interested in workplace charging would prefer to have a Level 1 outlet available over having no option for workplace charging. 


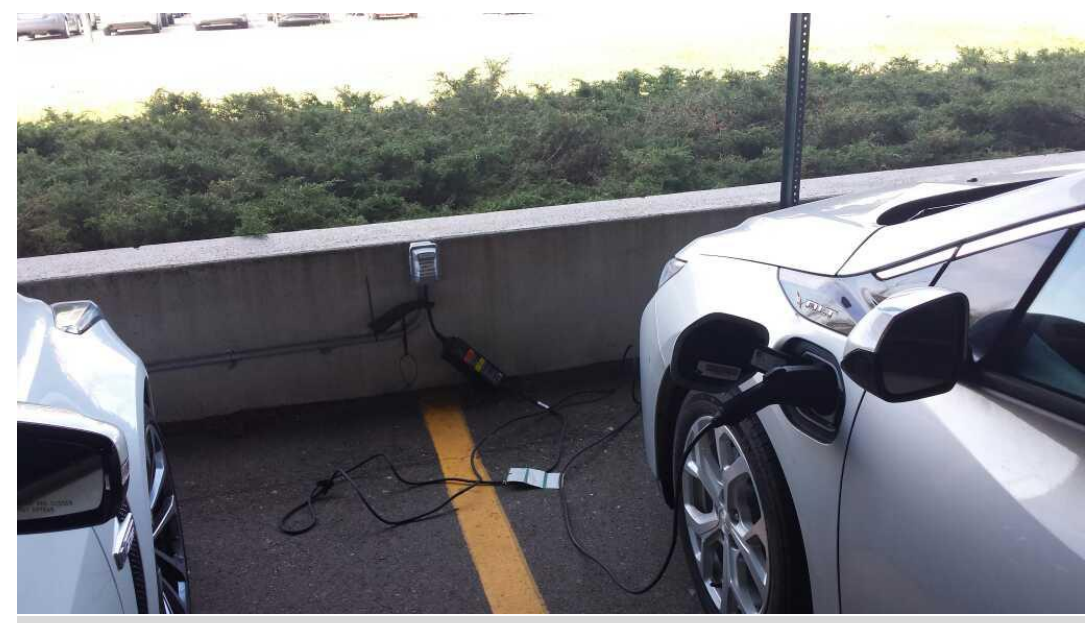

Photo 3. Over 150 Level 1 outlets are available for workplace charging at GM worksites.

Photo from GM.
Level 1 outlets used for PEV charging should be National Electrical Manufacturers Association (NEMA) commercial grade outlets that meet National Electric Code (NEC) requirements. ${ }^{5}$ These outlets must be on a dedicated circuit, preferably rated for 20 amps. $^{6}$ Using a ground fault circuit interrupter (GFCI) outlet with an outlet cover is required for outdoor use or anywhere the outlet could get wet. If an electrical outlet that does not meet

these requirements is used for PEV charging, there can be sparks, damage, or injury. An electrician can inspect an existing outlet to determine if it meets these specifications or install a new electrical outlet on a dedicated circuit. Products are also available that allow site hosts to install multiple electrical outlets mounted to a wall or a pedestal. This enables site hosts to place outlets in a convenient location for PEV drivers to plug in their portable Level 1 EVSE cordsets.

For an electrical receptacle to function safely, there needs to be sufficient tension to keep the plug securely inserted into the receptacle. ${ }^{7}$ Receptacle tension should be tested a minimum of every 12 months in electrical receptacles that are frequently used for plugging in and unplugging a cordset. This preventative maintenance step can identify safety hazards and avoid potential down time. Little data is available on the performance of different types of outlets used for Level 1 charging. Higher quality commercial grade outlets, such as hospital grade outlets, may be more durable and retain optimal tension longer than lower quality outlets.

Employers are encouraged to consider cordset weight and typical length of the cord when determining the Level 1 outlet height. Putting strain on the Level 1 outlet or the cordset by having the cordset hang in the air, as shown in Photo 4, should be avoided.

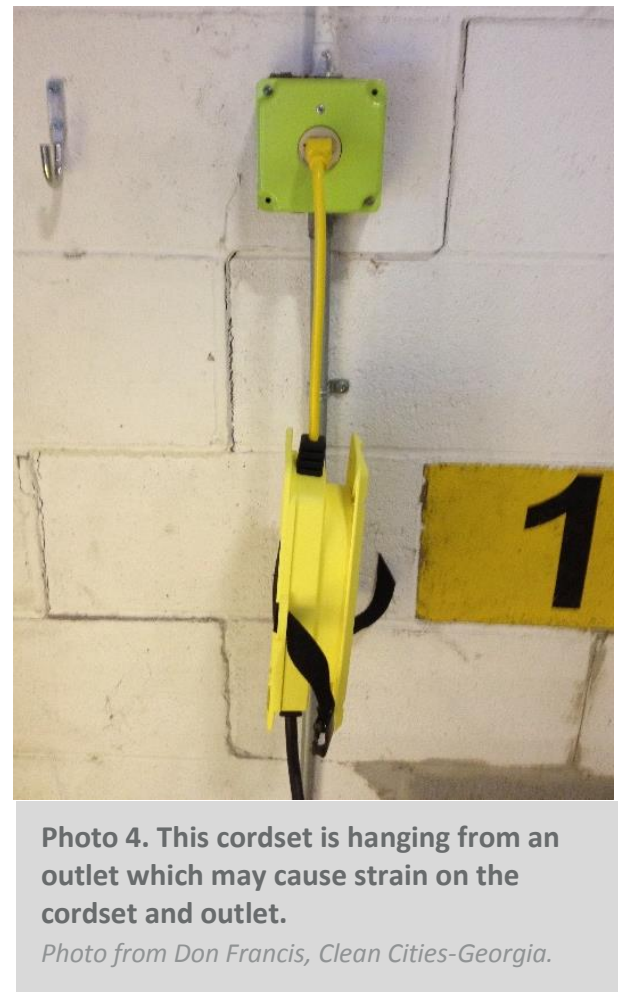

${ }^{5}$ Consult National Electric Code NFPA 70, 2014 edition, sections 210.17, 511.10, 625.1 and 625.44.

${ }^{6}$ Some cordsets are rated for 15 amps but many are 20 amps.

${ }^{7}$ The UL498 standard requires 3 lbs of retention force after 100 cycles of conditions. 
It should be noted that safety standards for standard residential and commercial outlets were not developed with repeated operations for charging plug-in electric vehicles in mind. The current safety standard that covers 120 volt/20 amp electrical outlets is UL 498, the Standard for Safety for Attachment Plugs and Receptacles. The protocol recommends that these electrical outlets (which are the type typically used for Level 1 charging) complete a number of tests to pass safety standards. These include tests in which the receptacle has a plug inserted and removed 250 times in various conditions without sustained flaming of the material in excess of five seconds duration.

\section{Workplace Charging Challenge Partner Examples}

\section{General Motors (GM) - Detroit, MI}

GM, a Workplace Charging Challenge Partner, started a workplace charging program in 2010 by installing over 100 Level 2 EVSE across key employee parking lots. A few years later, GM wanted to provide more charging stations to keep up with demand as more employees purchased new Chevrolet Volts. Not only did GM choose to expand its Level 2 offerings, but it also chose to start installing Level 1 outlets to maximize the number of employees that would have access to workplace charging while staying within available budgets. Installing Level 1 outlets cost

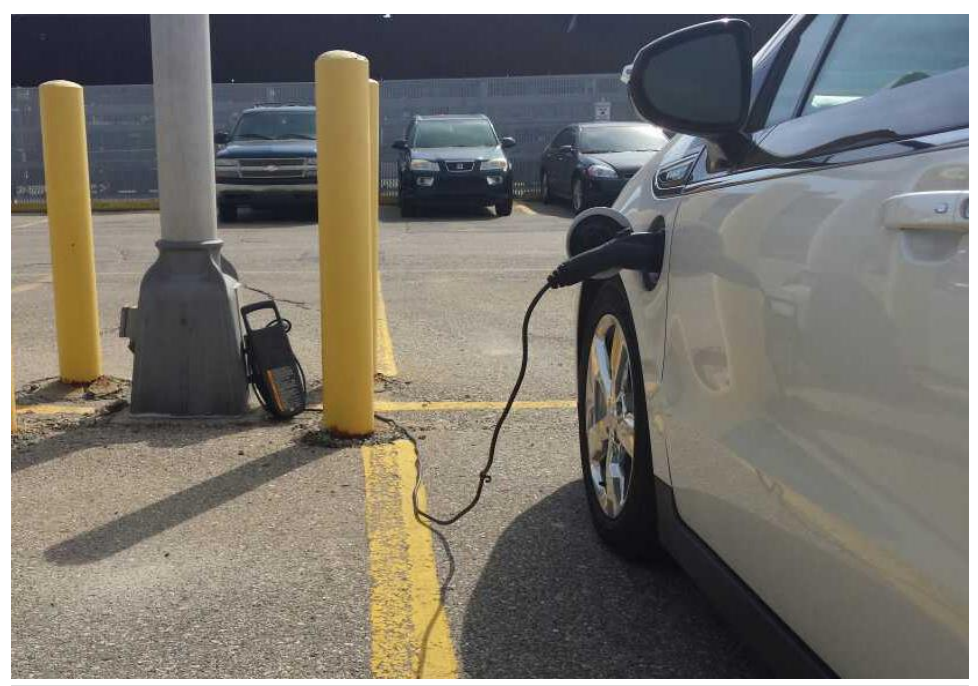

Photo 5. GM installs Level 1 outlets on parking lot lamp posts for convenient workplace charging. Photo from GM. significantly less than installing a Level 2 EVSE. GM reported a rule-of-thumb estimate in March 2016 of $\$ 10,000$ to install a Level 2 EVSE and \$1,000 to install a Level 1 outlet. Considering the available parking lot power supply, (generally) GM could install twice as many Level 1 outlets than Level 2 before it needed to pay for more costly electrical upgrades. Overall, choosing Level 1 outlets enabled GM to expedite workplace charging projects and provide workplace charging for many more employees than it could have if it only chose Level 2 EVSE.

Many of GM's employee parking lots are located a long distance away from employee work areas, and Michigan winters can be cold. Leaving a vehicle at a Level 1 charging station all day can be more convenient and a better use of an employee's time than having to move a vehicle mid-day to share a Level 2 EVSE.

GM now has over 150 Level 1 outlets for employee PEV charging and almost 350 Level 2 EVSE at its locations around the country as part of its free workplace charging program. Offering Level 1 outlets became such a successful strategy that it is now standard GM practice to install Level 1 outlets near a parking space whenever they can easily be added as part of electrical work on a building or parking lot. For example, a conversion of a parking lot lamp post to use more efficient lighting can also include 
installing several Level 1 outlets on the lamp post. The incremental cost of adding a Level 1 outlet is minimal when electrical work is already being done.

\section{Coca-Cola - Atlanta, GA}

The Coca-Cola Company, a Workplace Charging Challenge Partner, started its workplace charging program in 2012 by offering 12 Level 1 outlets in one of its parking garages. Spaces were in such high demand that Coca-Cola installed an additional 12 Level 1 outlets in a different parking garage. As employees continued to purchase PEVs, the company continued to install Level 1 outlets and now has 75 Level 1 charging stations spread over multiple parking garages. Coca-Cola chose Level 1 outlets because they were a low cost option and allowed employees to park at the charging station without having to return during the day to move their vehicle or EVSE connector. About 160 Coca-Cola employees drive PEVs and use the free workplace charging on a first-come, firstserve basis. Additionally, Coca-Cola has two Level 2 EVSE available for visitors and a DC fast charger (DCFC) station that can be reserved in 30 minute slots through a Microsoft Outlook room reservation tool. The DCFC provides piece of mind if there is not enough time for a vehicle to charge at a Level 1 outlet. It was donated by Nissan and has a CHAdeMO connector compatible with Nissan, Mitsubishi, and Kia electric vehicles. Generally, PHEVs do not have

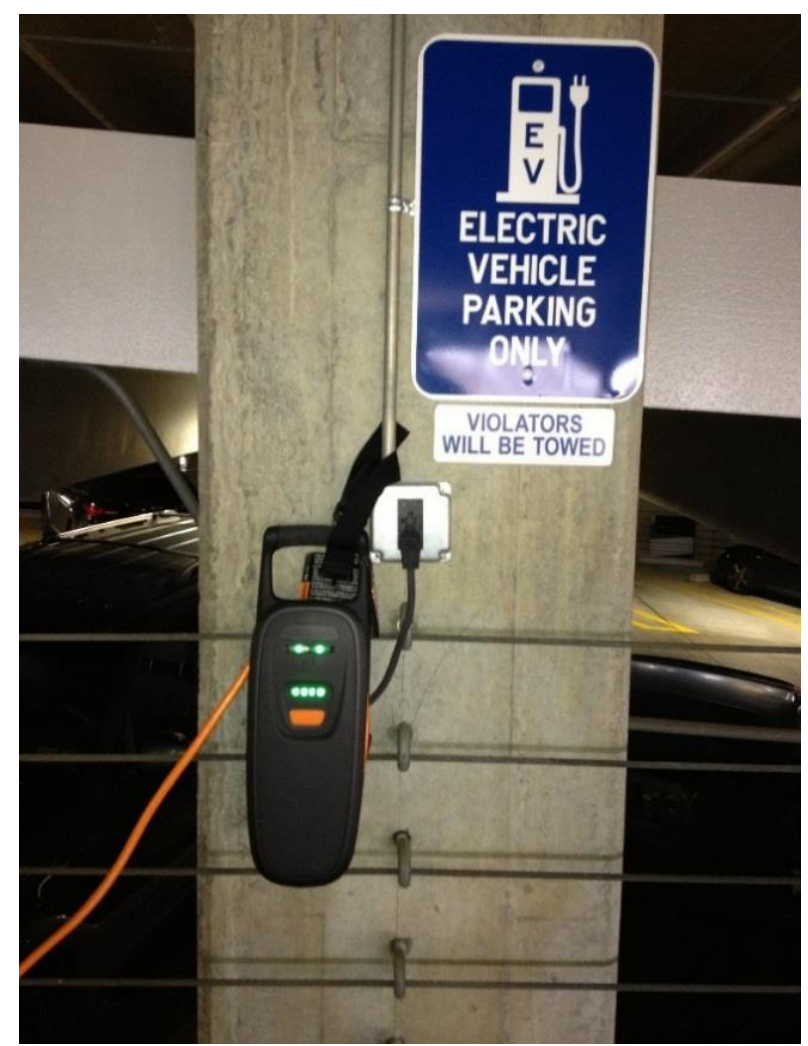

Photo 6. One of many highly visible Level 1 charging stations at Coca-Cola. The driver straps the cordset to the electrical conduit so there is no strain on the plug and outlet. The parking spot is well marked with an Electric Vehicle Parking Only sign. Photo from Don Francis, Clean Cities-Georgia.

DC fast charge capability, but they can run on gasoline if they run out of electric miles.

The Level 1 outlets are located about four feet off the ground and each parking space has an "Electric Vehicle Parking Only" sign for high visibility. One challenge from having the outlet so high is that the weight of the cordset may pull on the plug and outlet. Out of concern for the lifespan of the plug and outlet, some drivers strap their cordset to the electrical conduit to relieve the tension as shown in Photo 6.

\section{Estimated Costs for Scenario A (Making an Electrical Outlet Available)}

\section{Installation}

At some sites, there may already be a Level 1 outlet located near a parking spot that can be used for Level 1 charging. Before using it for charging, it is important to have an electrician inspect the outlet and confirm that it meets PEV charging requirements. If a new outlet or an upgrade to an existing $120 \mathrm{~V}$ 
circuit is needed, this may cost around \$200-\$500, assuming no unusual construction is needed. ${ }^{8}$ An employer may choose to install outlets along a row of parking spaces, as shown in Photo 7. Generally, the cost range for installing an outlet and dedicated circuit in a parking lot or garage is $\$ 300-\$ 1,000$ per outlet $^{9}$ (installing multiple outlets on a site can result drive costs toward the lower end of that range). If a site requires electrical service upgrades to accommodate the power used by PEV charging stations, installation costs may increase significantly. Electricians can provide estimates for a specific project.

Employers can minimize charging station installation costs by choosing a location close to the electrical service. Wayfinding signage can be used to direct drivers to the charging stations as an alternative to placing the charging station in a prominent location with a more costly installation. Station signage is used to help PEV drivers identify charging stations and communicate restrictions on which vehicles are allowed to use the parking spot. Station signage and painted parking spots can be especially helpful when offering a Level 1 outlet since the small outlet may not be noticeable to drivers. Visit the Workplace Charging Challenge website (http://www.energy.gov/eere/vehicles/workplace-charging-challengesignage-guidance) to find signage templates and learn how proper signage can optimize charging station usage.

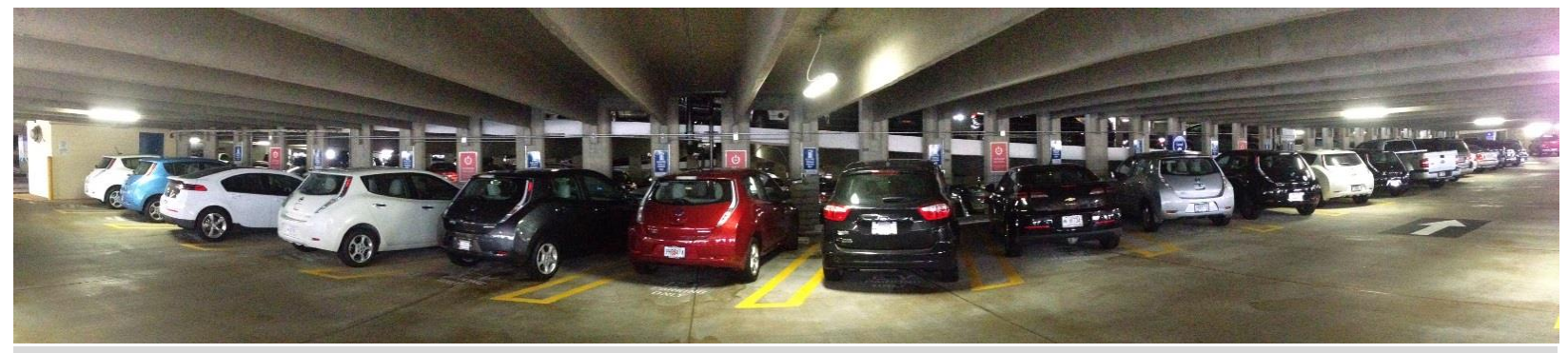

Photo 7. Electrical outlets are available along a row of parking stalls for PEV drivers to charge their vehicles using a Level 1 cordset.

Photo from Jonathan Kirchner, Coca-Cola.

\section{Electricity Consumption and Demand}

A major benefit to Level 1 charging is the lower electricity consumption costs compared to higher power charging options. Assuming drivers have a commute of 10-25 miles one-way, the potential electricity consumed by one Level 1 charging station could range from 867-2,167 kWh/year. Assuming a commercial electricity rate of 10.59 cents per kilowatt-hour ${ }^{10}$ results in an annual cost of \$92-\$229 electricity consumption for each Level 1 charging station.

In addition to consumption costs, many commercial and industrial sites may be subject to power demand charges from the utility. Each utility has its own threshold for demand charges, typically between 20 and $50 \mathrm{~kW}$. Once a site's power usage exceeds that threshold, the site is charged a fee based on the site's peak demand, regardless of the duration of that peak demand. Using PEV charging stations may result in

${ }^{8}$ Plug-In Electric Vehicle (PEV) Roadmap for North Carolina, North Carolina Plug-in Electric Vehicle Taskforce. February 2013

${ }^{9}$ U.S. Department of Energy, November 2015, Costs Associated with Non-Residential Electric Vehicle Supply Equipment http://www.afdc.energy.gov/uploads/publication/evse cost report 2015.pdf.

${ }_{10}$ Table 5.3 at http://www.eia.gov/electricity/monthly/pdf/epm.pdf 
higher demand fees by increasing the facility's peak electricity demand. Sites with charging stations can experience demand charges from $\$ 0$ to over $\$ 2,000 /$ month. This is more commonly a concern for sites that have DC fast charging or multiple Level 2 EVSE and rarely a concern for Level 1 charging. Contact the utility prior to charging station installation for information about demand charges and how they may be minimized or eliminated.

\section{Maintenance}

Over time, the commercial grade NEMA electrical outlet used with Level 1 cordsets may need to be replaced. Depending on the outlet age, type, and use, the outlet should function appropriately for many years. The cost of an outlet can range from $\$ 1-\$ 40$ depending on whether it is for an indoor or outdoor application, the quality level, and if it protects against electrical shock (GFCI rated). Estimated electrician's fees for replacing outlets are in the \$50-\$75 range, depending on how many outlets need to be changed and the labor rates in the geographic region.

\section{Sample Employee Fee for Scenario A (Making an Electrical Outlet Available)}

If an employer wants to recover the entire cost of offering workplace charging, providing a Level 1 outlet may be the best option for both employers and employees. The table below provides an example in which drivers pay \$11.67-\$17.50 per month (equivalent to \$0.54-\$0.81 per workday) to connect their own cordsets to electrical outlets. Actual costs will depend on the installation cost and the electricity consumption.

Table 1. Example for Recovering Level 1 Charging Costs when Making a Level 1 Electrical Outlet Available

\begin{tabular}{|c|c|c|}
\hline $\begin{array}{c}\text { SCENARIO A } \\
\text { Example for Recovering Level } 1 \text { Charging Costs }\end{array}$ & Annual Cost & Monthly Cost \\
\hline Electricity Consumption Cost for 1,039 kWh/yr* & $\$ 110 / y r$ & $\$ 9.17 / \mathrm{mo}$ \\
\hline $\begin{array}{l}\text { Installation for a Level } 1 \text { Outlet } \$ 300-\$ 1,000 * * \text { over } 10 \\
\text { years }\end{array}$ & $\$ 30-\$ 100 / y r$ & $\$ 2.50-\$ 8.33 / \mathrm{mo}$ \\
\hline PEV Driver Fee to Cover All Costs & $\$ 140-\$ 210 / y r$ & \$11.67-\$17.50/mo. \\
\hline
\end{tabular}




\section{Scenario B: Providing Level 1 EVSE}

\section{Overview}

Employers can install permanent wall mounted or pedestal mounted Level 1 EVSE so drivers do not have to provide their own cordsets. The additional expense of the EVSE increases the cost of this option relative to offering only a Level 1 outlet. Since drivers can leave their cordsets at home, this option is more convenient for employees, as there is no risk of personal property (cordset) theft or damage.

A simple installation could entail plugging a cordset into a Level 1 outlet and mounting the equipment on a wall. Alternatively, wallmounted or pedestal-mounted Level 1 EVSE can be hardwired to the electrical system. Placing the EVSE on a wall is generally the most cost-effective design because it avoids the costs of underground electrical conduit. It is also possible to install a pedestal-mounted Level 1 EVSE next to a parking space but this is often the highest cost Level 1 option.

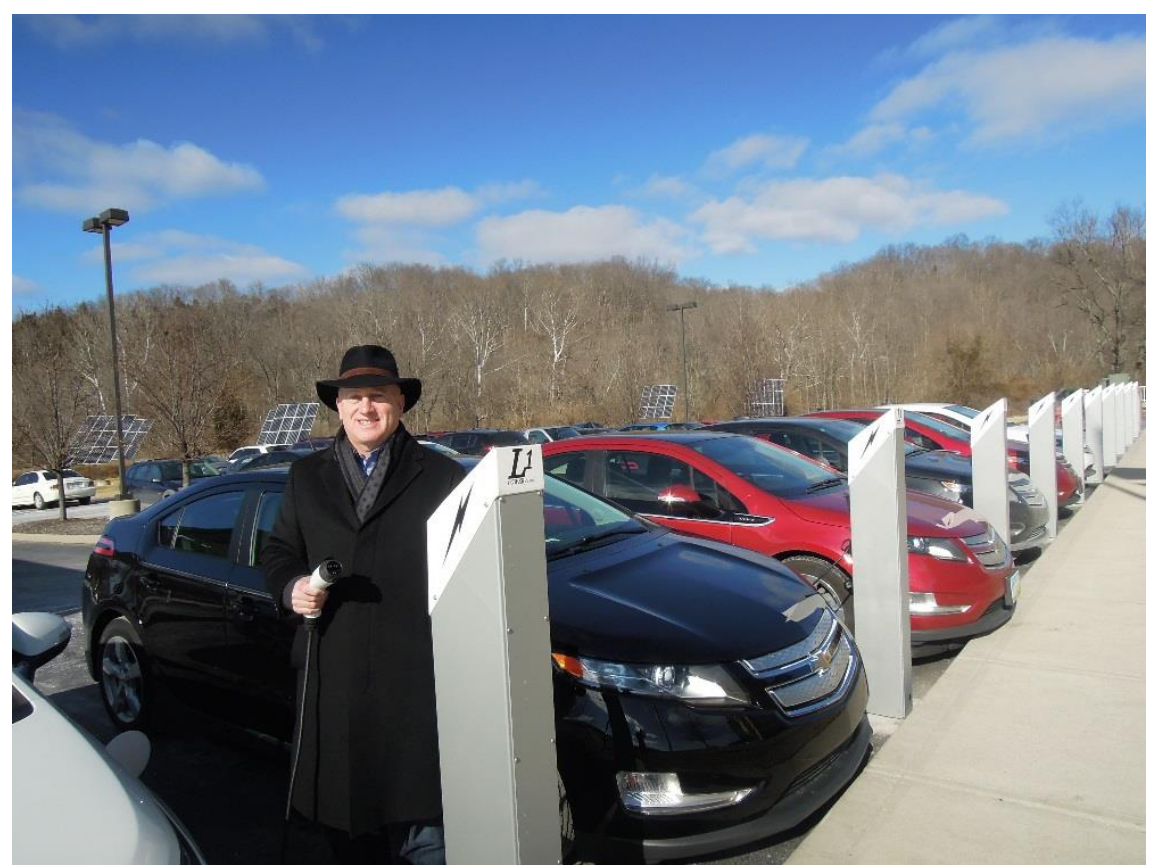

Photo 8. Steve Melink holding the connector of a Level 1 PowerPost part of Melink's workplace charging program. Photo from Melink.

Most Level 1 EVSE units are designed to simply charge a vehicle; they are not networked and do not have additional software features that track energy use, process payment for a charging session, or determine which drivers are authorized to use the EVSE. Secondary systems that provide these features can be installed to supplement the Level 1 EVSE. Employers that want to track EVSE energy use can install a monitoring product that tracks power consumption. A secondary system is available that can provide access control and payment features for Level 1 charging.

\section{Workplace Charging Challenge Partner Examples}

\section{Melink - Milford, OH}

Melink Corporation, a Workplace Charging Challenge Partner, is committed to reducing vehicle emissions and reliance on petroleum fuels. In an effort to share Melink's vision for sustainable transportation, it provides free charging for employees and visitors as well as an incentive for employees to purchase a PEV. Wanting to offer a variety of charging methods, the company installed ten Level 1 PowerPost EVSE and four Level 2 EVSE on its campus in December 2014. Testing a new product on 
campus had some challenges, but everything has been working smoothly after the electrical sub panel was upgraded in January 2015. As of April 2016, 80\% of the charging stations were occupied on a daily basis and Melink intends to install additional EVSE in the near future. The Melink headquarters is a Net-Zero Energy and LEED Platinum building. Melink uses a custom building monitoring system to track the energy used throughout the building down to the individual breaker. This monitoring system helps identify excessive energy consumption in the building and track the energy used by the free PEV charging.

\section{SAP - Palo Alto, CA}

When SAP, a Workplace Charging Challenge Partner, began planning its workplace charging program, managers conducted an employee survey to identify how many employees were interested in charging their vehicle at work. Based on the survey responses, SAP determined that PEV drivers would have sufficient time during the work day to replenish their batteries using Level 1 EVSE. Since the equipment and installation for Level 1 EVSE cost less than Level 2 EVSE, SAP installed 20 ChargePoint Level 1 EVSE (15 of them can charge two vehicles at the same time). Each parking space next to an EVSE is marked as EV charging only and signage is on the ground. Drivers have to sign up for an access card, but there is no fee for using the workplace charging. SAP's PEV community uses a wiki page to maintain a calendar for who will need to use the EVSE or when an EVSE unit will be down for maintenance.

SAP has 160 employees registered to use these 35 charging ports and the demand is increasing. This growing demand has been a challenge for SAP and is the reason the company may choose to install Level 2 EVSE in the future. With Level 2 EVSE, SAP could implement a system in which two employees can take turns using one EVSE. When discussing additional EVSE installations, SAP faced some internal management challenges - including whether future EVSE installation costs should come from the facilities budget or represent an amenity that could be paid from the human resources budget. It has also faced challenges from employees who do not drive PEVs and think that it is an unequitable practice to provide PEV drivers with front row parking and free fuel.

\section{Estimated Costs for Scenario B (Providing Level 1 EVSE)}

\section{Equipment Hardware}

Simple wall-mounted Level 1 EVSE units that plug into an outlet or can be hardwired to the electrical system cost around $\$ 300-\$ 600$. On the higher end of the Level 1 EVSE price range, a pedestal unit with access control costs about $\$ 1,500$. 


\section{Installation}

Charging station installation costs vary significantly and are influenced by how much electrical work is needed, how much trenching or boring is needed, and ancillary considerations like permitting, labor rates, and ADA requirements. Little data is available on the costs of installing Level 1 charging equipment. As an example, in North Carolina, an upgrade to a $120 \mathrm{~V}$ circuit is needed may cost $\$ 200-\$ 500$, assuming no unusual construction is needed..$^{11}$ Installing a wall-mounted Level 1 EVSE hardwired to the electrical service would also cost around $\$ 300-\$ 1,000$ assuming the unit is located within 50 feet of the electrical service and no trenching or complex electrical work is needed. The installation cost for pedestal-mounted

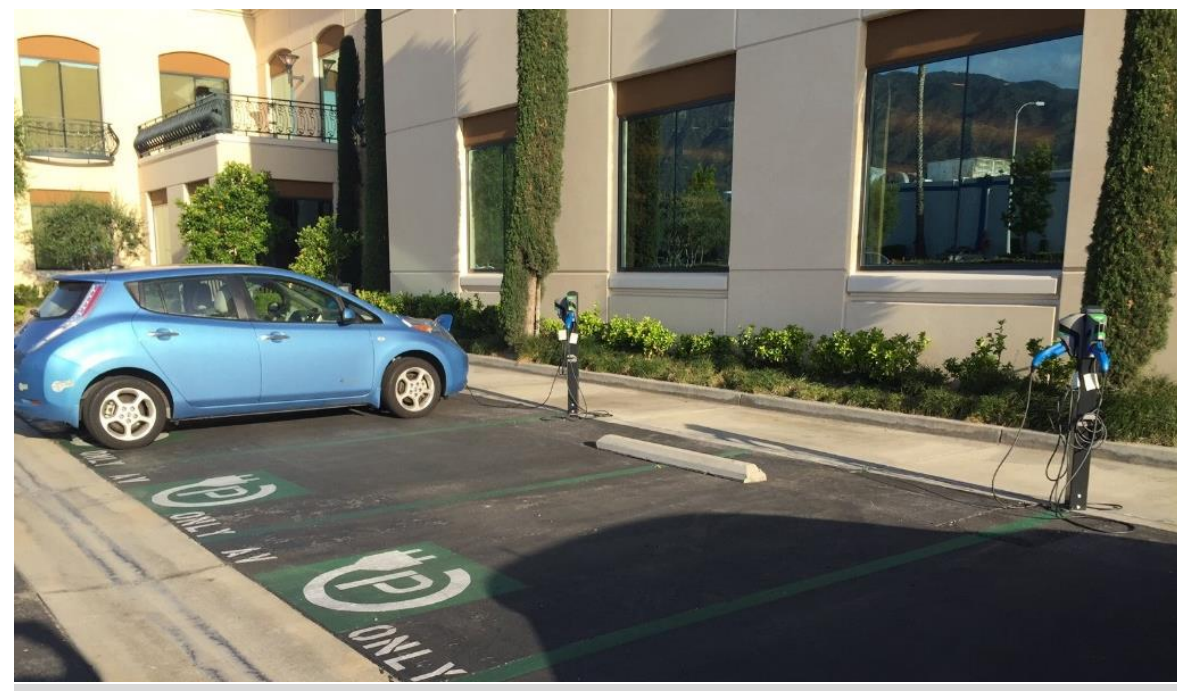

Photo 9. At AeroVironment's Monrovia office, they offer workplace charging using TurboDocks which can be used for Level 1 or Level 2 charging. Photo from AeroVironment

Level 1 EVSE will greatly depend on the selected location. Trenching or boring parking pavement to connect the EVSE to the electrical service can add a significant cost to the installation process. A ballpark cost range for a pedestal mounted Level 1 EVSE installation is $\$ 1,000-\$ 3,000$, assuming the unit is located within 50 feet of the electrical service and no major electrical upgrades are needed. If a site requires electrical service upgrades to accommodate the power used by PEV charging stations or extensive trenching, there may be a significant increase to installation costs. While there is little data on costs for installing pedestal-mounted Level 1 EVSE, the pedestal-mounted Level 2 EVSE units installed during the Department of Energy's EV Project had an average installation cost of \$2,305 with some installations costing over $\$ 4,000 .{ }^{12}$ To obtain estimates for a specific project, contact electricians and charging station manufacturers.

As noted above, employers can minimize charging station installation costs by choosing a location that is close existing electrical service. See the Costs for Scenario A section above for more information about signage. Visit the Workplace Charging Challenge website (http://www.energy.gov/eere/vehicles/workplace-charging-challenge-signage-guidance) to find signage templates and learn how proper signage can optimize charging station usage.

\footnotetext{
${ }^{11}$ Plug-In Electric Vehicle (PEV) Roadmap for North Carolina, North Carolina Plug-in Electric Vehicle Taskforce. February 2013

12 What were the Cost Drivers for Workplace Charging Installations?. https://avt.inl.gov/sites/default/files/pdf/EVProj/WhatWereTheCostDriversForWorkplaceInstallations.pdf
} 


\section{Electricity Consumption and Demand}

For information about electricity consumption and demands, see the Costs for Scenario A section above.

\section{Maintenance}

Since the PEV market is relatively new, little information is available about the maintenance costs or lifespan of EVSE. Regular maintenance is generally not required for Level 1 EVSE. If the EVSE is damaged due to vandalism or driving over a cord, it is more common to replace the damaged component than to try to repair it.

\section{Sample Employee Fee for Scenario B (Providing Wall-Mounted Level 1 EVSE)}

An employer may want to charge a fee to recover the costs of electricity, EVSE, and installation. In the example below, drivers would pay $\$ 14.17-\$ 22.50$ per month (equivalent to $\$ 0.65-\$ 1.04$ per workday) to offset the costs of electricity consumption and the EVSE. Actual costs will depend on which EVSE is selected, installation costs, and the electricity consumption.

Table 2. Example for Recovering Level 1 Charging Costs when Providing Wall-Mounted Level 1 EVSE.

\begin{tabular}{|c|c|c|}
\hline $\begin{array}{c}\text { SCENARIO B } \\
\text { Example for Recovering Level } 1 \text { Charging Costs }\end{array}$ & Annual Cost & Monthly Cost \\
\hline $\begin{array}{l}\text { Electricity Consumption Cost } \\
\text { for } 1,039 \mathrm{kWh} / \mathrm{yr}^{*}\end{array}$ & $\$ 110 / y r$ & $\$ 9.17 / \mathrm{mo}$. \\
\hline $\begin{array}{l}\text { Wall mounted Level } 1 \text { charging equipment with } \\
\text { cord and connector } \\
\$ 300-\$ 600 \text { over } 10 \text { years }\end{array}$ & $\$ 30-\$ 60$ & $\$ 2.50-\$ 5.00 / \mathrm{mo}$ \\
\hline $\begin{array}{l}\text { Installation for wall mounted Level } 1 \text { charging } \\
\text { equipment } \\
\$ 300-\$ 1,000^{* *} \text { over } 10 \text { years }\end{array}$ & $\$ 30-\$ 100 / y r$ & $\$ 2.50-\$ 8.33 / \mathrm{mo}$ \\
\hline PEV Driver Fee to Cover All Costs & $\$ 170-\$ 270 / y r$ & $\$ 14.17-\$ 22.50 / \mathrm{mo}$ \\
\hline $\begin{array}{l}\text { Average one-way commute (12 miles, } 2009 \text { National Highway Transp } \\
\text { ilowatt-hour, U.S. Department of Energy, } 2014 \text { PEV Models, www.fue } \\
\text { ents per kilowatt-hour, Energy Information Administration, } 2015 \text { Tab } \\
\text { * U.S. Department of Energy, November 2015, Costs Associated with } \\
\text { tttp://www.afdc.energy.gov/uploads/publication/evse cost report } 2\end{array}$ & $\begin{array}{l}\text { Survey, nhts.ornl.gov) } \\
\text { (.gov), Average comm } \\
\text { ttp://www.eia.gov/el } \\
\text { dential Electric Vehicl }\end{array}$ & $\begin{array}{l}\text { PEV efficiency ( } 3 \text { miles per } \\
\text { omer electricity price (10.59 } \\
\text { onthly/pdf/epm.pdf). } \\
\text { quipment }\end{array}$ \\
\hline
\end{tabular}




\section{Management Policies}

A clear and consistent management policy is important for any workplace charging program. It is especially important for Level 1 charging since employees often use their own cordsets and a lack of networked features such as communications capabilities places more reliance on management policy. Having an official written policy in place can make a difference between a successful workplace charging program and one that faces many problems. For instance, if an employer informally lets employees plugin their vehicles to a wall outlet without a written policy, that system could be disrupted if someone in authority objects to providing free electricity. Workplace Charging Challenge Partners have found the suggestions below helpful for managing a successful Level 1 workplace charging program.

\section{Administration}

Designate a responsible individual or group for ongoing charging station operation and maintenance issues, use clear and consistent signage and stall paint to indicate PEV parking designation, and identify which drivers have access to charging. Provide clear guidance on how workplace charging policy will be enforced. Read about laying the groundwork for a well-managed program on the Workplace Charging Challenge website: http://www.energy.gov/eere/vehicles/workplace-charging-management-policiesadministration

\section{Registration and Liability}

Have PEV-driving employees register their vehicles with the employer to participate in the workplace charging program. Consider adding liability language to the registration form to address employer and employee responsibilities when using the charging stations. Examples include prohibiting the use of extension cords and implementing other safety measures to avoid tripping hazards that may be associated with Level 1 outlets. Once registered, provide employees with rearview mirror hangtags or window stickers that signal they have permission to charge. Read simple sign-up procedures for helping employees get plugged in to workplace charging on the

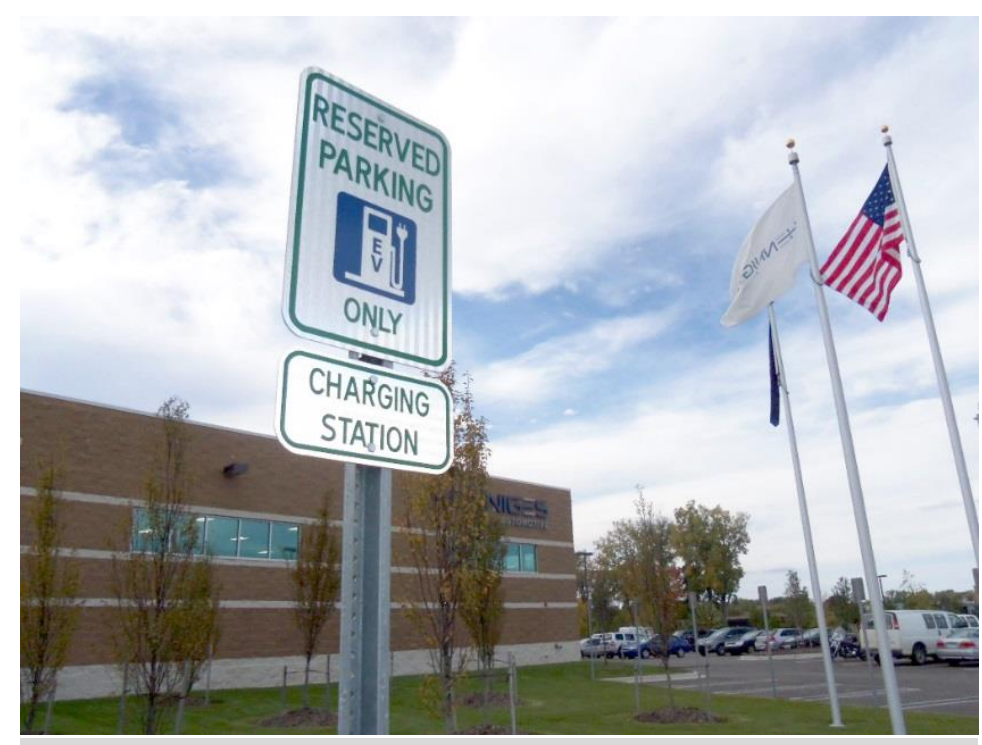

Photo 10. This signage makes it clear that the parking spot is reserved for electric vehicle charging. Photo from City of Auburn Hills, NREL 27653.

Workplace Charging Challenge website: http://www.energy.gov/eere/vehicles/workplace-charging management-policies-registration-liability 


\section{Charging Sharing}

A key reason why employers provide Level 1 charging is to avoid the need for employees to move their vehicles in order for others to charge over the course of the workday. In this case, the employer may find it helpful to either assign PEV drivers to a specific charging-capable parking stall or issue only a certain number of Level 1 charging permits. Read about charging sharing practices that mitigate problems when the number of employee-driven PEVs exceeds charging station availability on the Workplace Charging Challenge website:

http://www.energy.gov/eere/vehicles/workplacecharging-management-policies-sharing

\section{Pricing}

Many existing workplace charging programs are

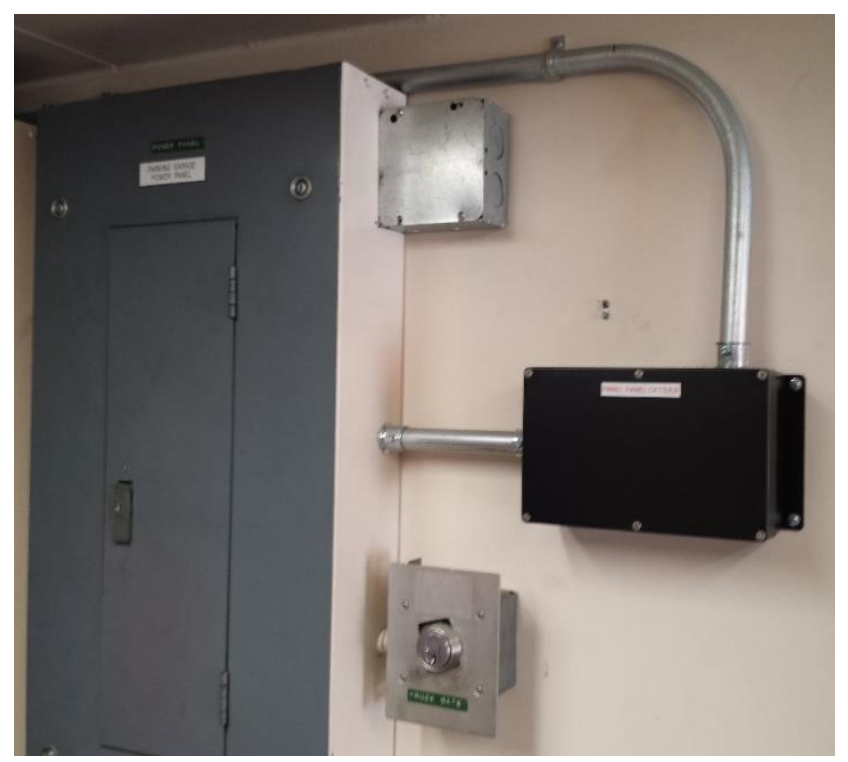

Photo 11. This energy monitor installed next to the control panel tracks energy consumption on up to 12 EVSE and provides access to the data through an online interface. Photo from Evolution Electric Vehicle Systems, LLC.

free for employees. As the number of PEVs expands, employers may implement a fee to discourage employees who do not truly need to charge at work from occupying the stations. Additionally, an employer may require a fee to recover some or all of the costs of offering workplace charging (electricity, installation, and hardware). Since Level 1 options often lack a fee-collection feature, the employer may choose to set a certain biweekly, monthly, or annual fee that can be collected in the employee's paycheck, alongside submission of their parking fee or at the time of PEV registration. Example fee structure can be found in the "Sample Employee Fee" sections above. Read about the advantages and disadvantages of fee-based and free employee charging on the Workplace Charging Challenge website: http://www.energy.gov/eere/vehicles/workplace-charging-management-policies-pricing

States are considering implementing a regulation (NIST HB44) that will require transaction reporting any time a driver is charged a fee for PEV charging (Level 1, Level 2, and DC fast charging). The EVSE would need to measure the energy used during the charging session and provide a kWh receipt via web, SMS text, QR code, etc. As of May 2016, this requirement is being implemented in California on an interim basis and other states are considering adopting it. Since this type of transaction reporting is not available for Level 1 charging, it is unclear how it will affect situations in which employers want to charge a fee for Level 1 charging.

\section{Comparing Level 1 and Level 2 EVSE}

The main difference between Level 1 and Level 2 EVSE is the charging speed. Since Level 2 EVSE uses higher power, it can replenish 10-20 miles of range in one hour of charging, with PHEVs typically on the lower end of the range. ${ }^{13}$ If a driver relies on workplace charging for the return commute and is at work

\footnotetext{
${ }^{13}$ Alternative Fuels Data Center - http://www.afdc.energy.gov/fuels/electricity_infrastructure.html
} 
for a shorter period of time than anticipated, having access to Level 2 EVSE may meet his or her needs, whereas Level 1 EVSE would not. An employer could consider a mixture of charging options with the Level 1 EVSE for those with typical work schedules and Level 2 EVSE available for emergency situations that require faster charging.

Although slower than Level 2 charging, there are many advantages to choosing Level 1 charging. The cost to install a charging station depends on many site-specific factors, but generally, installing a Level 1 station costs less than installing a Level 2 station. Some employers that offer Level 2 charging arrange for vehicles or connectors to be moved during the day to charge multiple vehicles on the same Level 2 EVSE. While this may be good fit for some organizations, others may prefer a workplace charging program that does not involve employees visiting the parking facility mid-day to tend to their vehicles. Each Level 1 station can be paired with one vehicle so there is no need to design and enforce a policy for moving cars or equipment during the day.

With an annual networking fee, networked Level 2 EVSE provide additional features such as communications capabilities, access control, point of sale, energy monitoring, and energy management. These features are not available on the lowest-cost tier of Level 1 EVSE. Some Level 1 EVSE on the higher end of the cost range do have access control systems. Secondary systems can be purchased to incorporate additional features such as access control, payment systems, and energy monitoring into a non-networked EVSE. These secondary systems can be useful if an employer wants to use Level 1 charging but also wants to have additional features that do not come with the EVSE. Since they have a

Table 3. Comparing Level 1 and Level 2 Charging

\begin{tabular}{|c|c|c|}
\hline & Level 1 & Level 2 \\
\hline Charging Speed & $\begin{array}{l}\text { 2-5 miles of range } \\
\text { in } 1 \mathrm{hr} \text {. }\end{array}$ & $\begin{array}{l}10-20 \text { miles of } \\
\text { range in } 1 \mathrm{hr} .\end{array}$ \\
\hline Costs & Generally lower & Generally higher \\
\hline $\begin{array}{l}\text { \# Vehicle Using } \\
\text { EVSE/Workday }\end{array}$ & 1 & 2 or more \\
\hline Access Control & $\begin{array}{l}\text { Available on some } \\
\text { units }\end{array}$ & $\begin{array}{l}\text { Available on some } \\
\text { units }\end{array}$ \\
\hline $\begin{array}{l}\text { Energy } \\
\text { Monitoring }\end{array}$ & $\begin{array}{l}\text { Not available on } \\
\text { unit*, but available } \\
\text { on secondary } \\
\text { system }\end{array}$ & $\begin{array}{l}\text { Available on some } \\
\text { units }\end{array}$ \\
\hline Point of Sale & $\begin{array}{l}\text { Not available on unit*, } \\
\text { but available on } \\
\text { secondary system }\end{array}$ & $\begin{array}{l}\text { Available on some } \\
\text { units }\end{array}$ \\
\hline
\end{tabular}

*Based on Level 1 EVSE units available in April 2016. one-time purchase cost instead of an annual fee, these products can be more cost effective than paying annual networking fees. An employer that is considering Level 1 charging and would like additional features should ask the EVSE manufacturer for recommended companies that offer secondary systems.

The site's overall electricity consumption, demand fee structure, and time of use rates may contribute to choosing between Level 1 and Level 2 charging. In some situations, a workplace may prefer to choose Level 1 over Level 2 EVSE since charging can be provided to more vehicles without pushing the site's peak electricity usage above the utility's threshold for demand fees. In

other situations, a workplace may prefer Level 2 over Level 1 EVSE since the vehicles can complete charging in the morning and not increase the site's afternoon peak demand, assuming a management policy that prohibits beginning a second round of charging mid-day. Time of use rates may also factor 
into the decision. Contact the electric utility to discuss demand fee rate structures and understand how different charging scenarios can affect your utility bill.

The site must have sufficient electrical capacity at the appropriate voltage flowing from the utility to the site's electrical panel to meet the charging stations' power needs. If the site does not meet these requirements, it will need electrical service upgrades. In some cases, electrical service upgrades have cost $\$ 10,000-\$ 25,000$, including installing a

Contact the electric utility to discuss demand fee rate structures and understand how different charging scenarios can affect your utility bill. new transformer and significant trenching. To avoid electrical service upgrades, employers are encouraged to choose the EVSE type and quantity that fit within the available electrical capacity. Since Level 1 EVSE draws less power than Level 2 EVSE, a site could install more Level 1 than Level 2 EVSE before meeting the limit of the electrical capacity. For example, a site that has $20 \mathrm{~kW}$ of available electrical capacity could install two $7.2 \mathrm{~kW}$ Level 2 EVSE or ten $1.9 \mathrm{~kW}$ Level 1 charging stations. Keeping in mind that most PEVs charge at a rate of $3.3 \mathrm{~kW}$ or 6.6 $\mathrm{kW}$ when using a Level 2 EVSE, installing $7.2 \mathrm{~kW}$ Level 2 EVSE may not be the ideal design. Lower power Level 2 EVSE are available, which could enable a company to install more EVSE without needing electrical upgrades. Since offering workplace charging encourages more employees to obtain PEVs for their work commute, employers should make decisions about the level and quantity of charging stations based on their expected long term need.

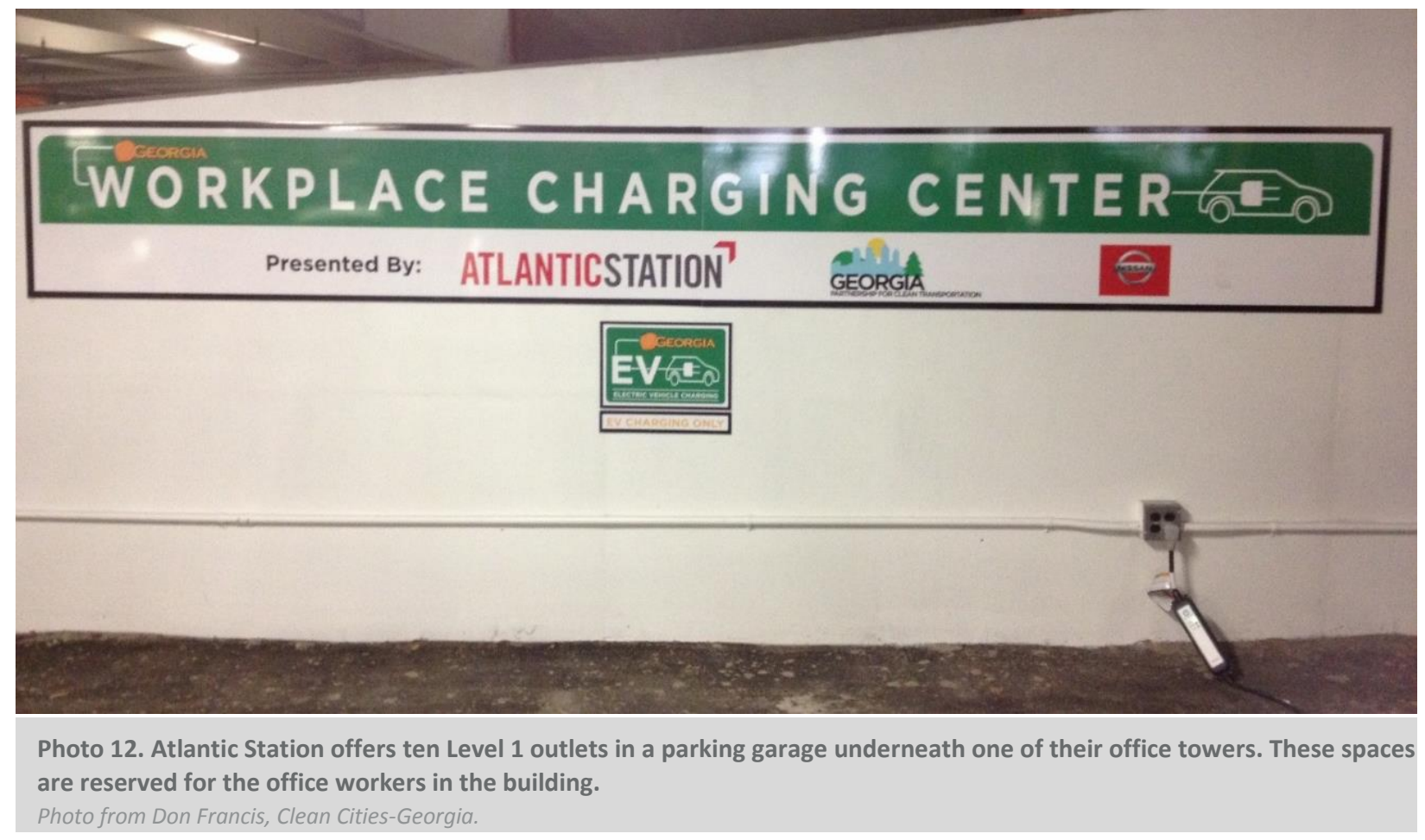

Successful workplace charging programs choose the charging station design that best fits the needs of the employer and employees. Taking into account the available budget, program goals, employee interest, and site specific requirements, Level 1 charging can be a great workplace charging solution. The low-cost option of simply providing a Level 1 outlet for employees to plug in their own cordset is a viable scenario 
for organizations that have minimal available capital and prioritize recouping all costs associated with workplace charging through relatively low employee fees. An employer may be able to cover the costs of offering a Level 1 outlet by charging employees \$11.67-\$17.50 per month. For increased convenience, installing Level 1 EVSE at the workplace can allow PEV drivers to replenish their batteries during the work day without needing to use a personal charging cordset. An employer may be able to cover the costs of offering a Level 1 EVSE by charging employees \$14.17-\$22.50 per month.

Well-thought-out and documented management policies are crucial for a workplace charging program to operate smoothly. Information about administration, registration and liability, charging sharing, and pricing can be found on the Workplace Charging Challenge website.

In addition to retaining talented employees, offering the option to charge PEVs during the workday can incentivize more employees to purchase PEVs. Replacing conventional vehicles with PEVs can reduce greenhouse gas and other emissions that contribute to climate change and smog while also saving drivers money and reducing the nation's dependence on petroleum. 


\title{
NOTICE
}

This report was prepared as an account of work sponsored by an agency of the United States government. Neither the United States government nor any agency thereof, nor any of their employees, makes any warranty, express or implied, or assumes any legal liability or responsibility for the accuracy, completeness, or usefulness of any information, apparatus, product, or process disclosed, or represents that its use would not infringe privately owned rights. Reference herein to any specific commercial product, process, or service by trade name, trademark, manufacturer, or otherwise does not necessarily constitute or imply its endorsement, recommendation, or favoring by the United States government or any agency thereof. The views and opinions of authors expressed herein do not necessarily state or reflect those of the United States government or any agency thereof.

This report is available at no cost from the National Renewable Energy Laboratory (NREL) at www.nrel.gov/publications

Available electronically at SciTech Connect http://www.osti.gov/scitech

Available for a processing fee to U.S. Department of Energy and its contractors, in paper, from:

\author{
U.S. Department of Energy \\ Office of Scientific and Technical Information \\ P.O. Box 62 \\ Oak Ridge, TN 37831-0062 \\ OSTI http://www.osti.gov \\ Phone: 865.576.8401 \\ Fax: 865.576.5728 \\ Email: reports@osti.gov
}

Available for sale to the public, in paper, from:

\author{
U.S. Department of Commerce \\ National Technical Information Service \\ 5301 Shawnee Road \\ Alexandria, VA 22312 \\ NTIS http://www.ntis.gov \\ Phone: 800.553 .6847 or 703.605 .6000 \\ Fax: 703.605.6900 \\ Email: orders@ntis.gov
}




\section{U.S. Department of Energy's Workplace Charging Challenge}

In March 2011, President Obama announced the EV Everywhere Grand Challenge, which is a Clean Energy Grand Challenge to PEVs that are as affordable and convenient for the American family as gasoline-powered vehicles by 2022. To help accomplish this goal, the Workplace Charging Challenge encourages U.S. employers in all sectors of the economy to provide PEV charging access at their worksites.

The Workplace Charging Challenge provides resources, tools, and technical assistance to implement and manage workplace charging programs, and Challenge partners are nationally recognized for their sustainability efforts. For more information on workplace charging or becoming a partner, contact the Challenge atworkplacecharging@ee.doe.gov. 